\title{
The Profile of Uropathogens and their Antibiotic Susceptibility in IPD Adults in a Tertiary Care Hospital in North India
}

\author{
Pooja Gupta $^{1^{*}}$ and Kashish Gupta ${ }^{2}$ \\ ${ }^{1}$ Department of Microbiologist, Max superspeciality Hospital, Bathinda-151001, \\ Punjab, India \\ ${ }^{2}$ Department of Ophthalmology, Max superspeciality Hospital Bathinda-151001, \\ Punjab, India \\ *Corresponding author
}

\section{A B S T R A C T}

Urinary tract infections (UTI) are one of the most common infections that lead to morbidity in humans with Escherichia coli being the most common bacteria. Injudicious use of antibiotics has led to increased resistance of urinary pathogens to otherwise

\section{Keywords}

Uropathogens, MDR, E.coli, antibiotic susceptibility

\section{Article Info}

Accepted: 22 May 2018 Available Online: 10 June 2018 sensitive antibiotics hence; Knowledge of local bacteriological trend the antibiotic susceptibility pattern is a must to initiate a judicious antibiotic treatment. The study was a retrospective analysis of urine samples of IPD patients done over a period of 7 months from June 2017 to Dec 2017. This was done to analyze bacteriological profile and their antibiotic susceptibility. 210 samples showed growth; 111 and 99 being females and males respectively. Gram negative bacteria were the most common isolates with E.coli being the most common bacteria followed by Klebsiella spp., Enterococcus fecalis and Pseudomonas aeruginosa comprising the majority of isolates. High sensitivity was observed towards nitrofurantoin while organisms were resistant to fluroquinolones. Cefoperazone-sulbactam and fosfomycin are also effective drug for E.coli and Klebsiella spp. UTIs were most common in females. Gram negative bacteria were the major uropathogens in our admitted patients; Escherichia coli and Klebsiella being the most common. An increased resistance was observed towards fluroquinolones, cotrimoxazole and cephalosporins. An antibiogram specific for healthcare setting is must that shall be based on bacteriological profile and organism's sensitivity pattern.

\section{Introduction}

Urinary tract infections (UTI) are the most common bacterial infections seen in tertiary care hospitals (Hooton, 2012). UTI in human are showing increasing trends in spite of use of antibiotics, in all age groups and both gender (Orhue, 2014; Shah et al., 2015). UTI is the most common type of nosocomial infection; $50 \%$ of patients with indwelling catheters have UTI with multidrug resistant (MDR) bacteria (Preethishree et al., 2016). Nosocomial UTI is major cause of morbidity and sepsis. It accounts for almost $40 \%$ of all nosocomial infections (Singhal et al., 2014). Bacteria are the major causative organisms; 95\% of UTI cases (Singhal et al., 2014). Most common etiologic bacteria are E.coli, 
Klebsiella pneumoniae, Pseudomonas aeruginosa, Proteus especially E.fecalis and Staphylococcus aureus (Orhue, 2014).

Generally the treatment for UTI is empirical, before the culture reports are available. This, unfortunately has led to emergence of MDR uropathogens. In addition, the extensive use of antibiotics, for infections outside the urinary tract, would alter the antibiotic susceptibility pattern of the intestinal bacteria that are generally implicated as uropathogens (Uwaezuoke and Ogbulie, 2006) It is very important to be aware of trend of most common bacteria causing UTI and also their antibiotic susceptibility pattern (Bency et al., 2017). Hence, this antibiogram shall be of great help to the clinicians and they shall ideally prescribe empirical antibiotics as per the updated trend in their city or hospital.

\section{Materials and Methods}

The study was a retrospective descriptive study conducted in admitted patients of a tertiary care hospital over a period of seven months from June 2017 to Dec 2017. The analysis of the reports was done at the microbiology department. All positive urine culture and sensitivity reports of admitted patients were included in the study. Patients were selected regardless of age and sex. The samples were plated on Blood Agar (Himedia) and MacConkey Agar media (Himedia) by the semi-quantitative plating method using the calibrated loop technique $(0.001 \mathrm{~mL})$. Plates were incubated aerobically overnight at $37^{\circ} \mathrm{C}$. The antibiotics were used as per the strips suitable for the kind of growth.

A total of 210 positive urine culture reports were reported when cultured using standard microbiological techniques [Collee and Marr, 1996]. Pure growth of an isolate in a count of $\geq 10^{5}$ colony forming units (CFU) per milliliter of urine was considered as significant bacteriuria (Bency et al., 2017). Organisms were identified by automated system ATB reader and their antibiotic susceptibility was done as per latest CLSI guidelines 2017 (Clinical and laboratory standards institute, 2017). Exclusion criteria were the isolates identified as contaminant or same isolates from repeat culture of patient those organisms which showed resistance to at least three or more antibiotics of different structural classes were considered MDR as described elsewhere [Pankaj Baral et al., 2012].

\section{Results and Discussion}

A total of 210 positive urine samples were obtained during our study period, in adult age group. Out of 210, 193 were bacteria while 17 isolates were Candida spp. Gender wise, 111 were female while 99 were males accounting for $52.5 \%$ and $47.5 \%$ respectively. Male to female ratio was $1: 1.1$. In our study, we isolated 193 bacteria and 17 Candida spp.

Among the bacterial profile of UTI, Escherichia coli was the most common bacteria accounting for $50.25 \%$ followed by Klebsiella spp. (24.35\%), Enterococcus spp.(9.85\%) and Pseudomonas aeruginosa (7.25\%); Staphylococcus aureus, Proteus mirabilis and Acinetobacter baumannii comprised the rest of bacteria.

Out of 111 females, E.coli was isolated from $46 \%$ and Klebsiella $24.3 \%$ while out of 99 males, E.coli was isolated from $46.5 \%$ while Klebsiella from $20.2 \%$.

Table 5 shows the antibiotic sensitivity pattern of gram negative bacteria and gram positive cocci respectively. Most of E.coli isolates were sensitive strains with maximum susceptibility to Carbapenems (85\%), fosfomycin $(85 \%)$ and nitrofurantoin $(76 \%)$ with reasonable sensitivity towards amikacin $68 \%$, and piperacillin tazobactam (66\%). Less 
susceptibility was observed for cephalosporins and fluroquinolones. Proteus isolates were also sensitive to higher cephalosporins, carbapenems and fluroquinolones. On the other hand Klebsiella isolates and Acinetobacter spp. were resistant to lower antibiotics namely cephalosporins, aminoglycosides, Fluroquinolones and cotrimoxazole. While some K.pneumoniae isolates showed susceptibility to carbapenems, A.baumannii was only sensitive to colistin other than just $15 \%$ susceptibility to imipenem and meropenem.

Amongst GPC, $100 \%$ sensitivity was observed towards higher antibiotics; linezolid, vancomycin and teicoplanin, moderate susceptibility towards amikacin and nitrofurantoin while most of the isolates were resistant to beta lactams and fluroquinolones.

Urinary tract infection is a common bacterial disease, often contributes to a frequent cause of morbidity in out-patients as well as hospitalized-patients (Wagenlehner and Naber, 2006). Clinical experience has indicated the presence of numerous cases of antibiotic resistance to common antibiotics by uropathogens in both developed and developing countries (Gupta, 2002). Continuous surveillance of antibiotic surveillance patterns of uropathogens at local level is crucial in dealing with emerging problems of antibiotic resistance and provides assistance in managing effective initial therapy (Bano et al., 2014).

A total of 210 positive IPD urine culture samples were reported during our 7 month study. Our finding of female preponderance is consistent with several other studies done by Sharma et al., (2011), Orhue (2014), Shah et al., (2015), Preetishree et al., (2016) and Jubina et al., (2017). All the studies noticed the UTI to be common in females; this finding can be due to short urethra in females.
(Preethishree et al., 2016) Gender wise, the isolation rate of E.coli in males and females was 46.5 and $46 \%$ which was almost comparable while klebsiella isolates were more common in females $(24.3 \%)$ as compared to males (20.2). Bency et al., (2017) reported bigger number of E.coli isolates in females; being $79.7 \%$ as compared to $64.9 \%$ in males.

In our study, E.coli was the most predominant bacteria $(50.25 \%)$ followed by Klebsiella pneumoniae $(24.35 \%)$. The preponderance of E.coli has been reported in studies done by Eshwarappa et al., (2011) (66.9\%), Hussein (2014) (39\%), Shah et al., (2015) (61.02\%), Preetishree et al., (2016) (57.14\%). Various studies have reported varying range of E.coli isolation; while Bency et al., (2017) reported $74.3 \%$ of isolation, Razak and Gurushantappa (2012) reported the percentage to be $37.95 \%$.

The second most common isolate was Klebsiella pneumoniae (24.35\%). Several other studies also had same trend. While Razak and Gurushantappa (2012) and Patel and Garala (2014) reported percentage of isolation $21.41 \%$ and $23.89 \%$ respectively, studies done by Shah et al., (2015), Eshwarappa et al., (2011), Preetishree et al., (2016) and Singhal et al., (2014) reported low percentages of $13.56 \%, 15.5 \%, 17.62 \%$ and $11 \%$ respectively.

While our all Staphylococcus isolates were S.aureus, Preetishree et al., (2016) study had isolated 19 of S.aureus of all Staphylococcus species and 6 isolates were coagulase negative staphylococcus (CONS), and in Singhal et al., (2014) study, CONS were the second most common isolates $(16.8 \%)$ in IPD patients while Klebsiella spp was the third most common. $100 \%$ S.aureus isolates in our study could be attributed to presence of urinary catheter in those patients. 
Table.1 Sex wise distribution of UTI

\begin{tabular}{|l|c|c|}
\hline Sex & Number & Percentage \\
\hline Male & 99 & 47.5 \\
\hline female & 111 & 52.5 \\
\hline
\end{tabular}

Table.2 Distribution of urinary isolates

\section{Distribution of Urinary Isolates $(\mathrm{n}=\mathbf{2 1 0})$}

\begin{tabular}{|l|c|c|}
\hline \multicolumn{1}{|c|}{ Isolate } & Numbers & $\%$ \\
\hline Bacteria & 193 & 91.90 \\
\hline Candida & 17 & 8.10 \\
\hline
\end{tabular}

Table.3 Bacterial profile of UTI

\begin{tabular}{|l|c|c|}
\hline \multicolumn{3}{|c|}{ Bacterial Profile of UTI (n=193) } \\
\hline & Number & Percentage \% \\
\hline E.coli & 97 & 50.26 \\
\hline Klebsiella pneumoniae & 47 & 24.35 \\
\hline Enterococci fecalis & 19 & 9.84 \\
\hline P.aeruginosa & 14 & 7.25 \\
\hline S.aureus & 7 & 3.63 \\
\hline Proteus mirabilis & 7 & 3.63 \\
\hline A.baumannii & 2 & 1.04 \\
\hline Grand Total & $\mathbf{1 9 3}$ & $\mathbf{1 0 0}$ \\
\hline
\end{tabular}

Table.4 Sex wise uropathogen distribution

\begin{tabular}{|l|}
\hline Organism \\
\hline E.coli \\
\hline Klebsiella pneumoniae \\
\hline E.fecalis \\
\hline Pseudomonas aeruginosa \\
\hline S.aureus \\
\hline Proteus mirabilis \\
\hline A.baumannii \\
\hline Candida spp. \\
\hline Total \\
\hline
\end{tabular}

\begin{tabular}{|c|c|c|}
\hline Male (\%) & Female (\%) & Total \\
\hline $46(46.5 \%)$ & $51(46 \%)$ & 97 \\
\hline $20(20.2 \%)$ & $27(24.3 \%)$ & 47 \\
\hline $9(9.09 \%)$ & $10(9.0 \%)$ & 19 \\
\hline $8(8.08 \%)$ & $6(5.4 \%)$ & 14 \\
\hline $4(4.04 \%)$ & $3(2.7 \%)$ & 7 \\
\hline $3(3.03 \%)$ & $4(3.6 \%)$ & 7 \\
\hline $2(2.02 \%)$ & 0 & 2 \\
\hline $7(7.07 \%)$ & $10(9.0 \%)$ & 17 \\
\hline 99 & 111 & 210 \\
\hline
\end{tabular}


Table.5 Antibiotic susceptibility pattern of gram positive and gram negative isolates

\begin{tabular}{|c|c|c|c|c|c|}
\hline & Pathogens & $\begin{array}{l}\text { No. of } \\
\text { isolates }\end{array}$ & $\begin{array}{c}\% \text { of } \\
\text { isolates }\end{array}$ & Sensitive & \\
\hline 1. & E.coli & 97 & 50.25 & $\begin{array}{c}\text { Fosfo( } 85 \%), \text { CfS(72\%), I,Mr (85\%), } \\
\text { Nf }(76 \%) \text { PTz (68), Ak (68\%) }\end{array}$ & Penic \\
\hline 2. & $\begin{array}{c}\text { Klebsiella } \\
\text { pneumoniae }\end{array}$ & 47 & 24.35 & $\begin{array}{c}\operatorname{Col}(100 \%), \operatorname{Fosfo}(75), \mathrm{I}, \operatorname{Mr}(62 \%) \\
\operatorname{CfS}(62),\end{array}$ & $\begin{array}{r}\text { Cephalos } \\
\text { Amin }\end{array}$ \\
\hline 3. & $\begin{array}{l}\text { Enterococcus } \\
\quad \text { fecalis }\end{array}$ & 19 & 9.85 & $\begin{array}{c}\text { Va, Lz, } \text { Tei(100\%),Nf(68\%), } \\
\text { Tetra(62\%), }\end{array}$ & \\
\hline 4. & $\begin{array}{l}\text { Pseudomonas } \\
\text { aeruginosa }\end{array}$ & 14 & 7.25 & $\operatorname{Col}(100), \mathrm{I}, \operatorname{Mr}(80), \operatorname{Ak}(52)$, & Cephal \\
\hline 5. & S.aureus & 7 & 3.6 & $\begin{array}{c}\text { Va, Lz, Tei(100\%), Tetra(65\%), } \\
\text { Nf(56\%), CoT(45) }\end{array}$ & $\mathrm{Cz}, \mathrm{E}$ \\
\hline 6. & Proteus mirabilis & 7 & 3.6 & $\begin{array}{c}\mathrm{I}, \operatorname{Mr}(100),, \mathrm{Caz}, \mathrm{Cpm}(84), \mathrm{G}(70), \\
\mathrm{Cip}(52)\end{array}$ & \\
\hline 7 & $\begin{array}{l}\text { Acinetobacter } \\
\text { baumannii }\end{array}$ & 2 & 1.03 & $\operatorname{Col}(100 \%)$ & $\begin{array}{r}\text { Carb } \\
\text { Aminoglyco }\end{array}$ \\
\hline & \multicolumn{5}{|c|}{$\begin{array}{l}\text { Ak=Amikacin, } \mathrm{G}=\text { Gentamycin, Cip=Ciprofloxacin, I=Imipenem, } \mathrm{Ar} \\
\text { trimoxazole, Col-colistin, } \mathrm{Mr}-\mathrm{Meropenem,} \mathrm{FQ-} \mathrm{fluroquinolones} \mathrm{(cip,} \\
\text { vancomycin, Lz (linezolid), Tei- teicoplanin, tetra- tetracycline, Fosfo= } \\
\text { cefoperazone sulbactam, Nf- nitrofurantoin, P- penicillin } \\
\text { Fig.1 Bacterial profile of UTI }\end{array}$} \\
\hline
\end{tabular}

17 out of 210 isolates were Candida spp. accounting for $8 \%$ of all uropathogens. Singhal et al., (2014) have reported $13.3 \%$ of Candida spp. in their IPD isolates.

The significant percentage could be due to the presence of factors predisposing for fungal infections in IPD patients, like long-term antibiotic treatment, steroids, chronic illness,
Resistant

Penicillins, FQ, G,

phalosporins,FQ,,CoT, Aminoglycosides

P, FQ, CoT

Cephalosporins, G, FQ

zz, E, Cip, Penicillins

CoT, Nf

Carbapenems, FQ, 
al., study where E.coli was $90.6 \%$ susceptible to Nitrofurantoin while only $16.3 \%$ sensitive to ciprofloxacin. Preetishree et al., also reported similar kind of pattern; $28.3 \%$ and $85.8 \%$ sensitivity to ciprofloxacin and nitrofurantoin respectively. This finding is in contrast with a south India study where Arjunan et al., (2010), have reported the low susceptibility to nitrofurantoin $(38.8 \%)$ and relatively high susceptibility to norfloxacin (94.4\%) and ciprofloxacin (77.7\%).

In studies done by Bency et al., and Preetishree et al., Klebsiella isolates were quite sensitive to Amikacin, Piperacillin tazobactam, gentamicin while our Klebsiella isolates were mostly resistant to all these drugs. Most of our Klebsiella isolates were multi drug resistant; they showed sensitivity to carbapenems (60-65\%), fosfomycin (75\%) and $100 \%$ sensitivity to polymyxins. This wide geographic variation reemphasises the requirement of knowledge of uropathogens and their sensitivity pattern.

Amongst GPC isolates, 100\% sensitivity was observed towards vancomycin and Linezolid; finding similar to most of the studies (Preethishree et al., 2016; Singhal et al., 2014; Bency et al., 2017). S.aureus also showed moderate sensitivity to Cotrimoxazole (45\%), Gentamicin (50\%), nitrofurantoin $(56 \%)$ and tetracycline $(65 \%)$. Least sensitivity was for ciprofloxacin (28\%). These findings are similar to Preetishree et al., (2016), Singhal et al., (2014).

Enterobactericeae showed a high sensitivity to fosfomycin and cefoperazone sulbactam. Out of all the isolates only E.coli and S.aureus were sensitive to Cotrimoxazole (35-45\%) while rests were resistant.

Overall, sensitivity of all isolates was less to fluroquinolones and also cephalosporins except Proteus spp. Because a very high percentage of isolates in this study were sensitive to nitrofurantoin, this drug would be a better choice for the empiric treatment of UTI [Hooton, 2012; Singhal et al., 2014].

In our study Klebsiella and Acinetobacter spp. were MDR while rest of the isolates was quite sensitive except to the beta lactam antibiotics, fluroquinolones.

Gram negative bacteria as the most common uropathogens and resistance of gram negative bacteria to fluroquinolones has been reported in lot of studies but the multidrug resistant property of klebsiella isolates is alarming.

The limitation of the study is that the study was of short duration and a retrospective one. The results are not applicable to generalized healthcare settings since the findings are from a single tertiary care hospital. Also, samples from all the areas were included in the study; the population included both the catheterized and non-catheterized patients.

The high prevalence of UTI was observed in females. Gram negative bacteria form the predominant uropathogen isolates in our set up with E.coli being the commonest; the worrisome being Klebsiella isolates which were resistant to most of the available antibiotics. Again, an increasing rate of resistance has been observed towards cotrimoxazole and fluroquinolones. Clinicians shall be aware of local bacteriological profiles and their antibiotic sensitivity pattern since that helps them in initiation of an appropriate antibiotic therapy. Thus an updated antibiogram for a hospital and timely urine culture are the keys to reduce emergence of resistant microbes in patients with suspected UTI.

\section{Acknowledgement}

I would like to extend thanks to administration of Max hospital, Bathinda and 
special thanks to my technicians who supported me in doing my work.

\section{References}

Arjunan M, Al-Salamah AA, Amuthan M. Prevalence and antibiotic susceptibility of uropathogens in patients from a rural environment, Tamil Nadu. Am J Infect Dis. 2010; 6: 29-3.

Bano S, Tunio SA, Menom AA, Detho H, Bano R, Kumari K. Evaluation of antibiotic susceptibility patterns of uropathogens circulating in Hydrabad, Pakisthan. Khyber Med Univ J. 2014; 6(3): 110-5.

Bency JAT, Priyanka R, Jose P. A study on the bacteriological profile of urinary tract infection in adults and their antibiotic sensitivity pattern in a tertiary care hospital in central Kerala, India. Int J Res Med Sci 2017; 5: 666-9.

Clinical and laboratory standards institute (CLSI). Performance standards for antimicrobial susceptibility testing; twenty seventh informational supplement. CLSI document. 2017 M100-S2.

Collee JG, and Marr W. culture of bacteria. In: Marmion BP, Fraser AG, Simmons A, editors. Mackie and Mccartney's practical medical microbiology. 14th ed. New York: Churchill Livingstone; 1996. pp. 113-30.

Eshwarappa, M., Dosegowda, R., Aprameya, I.V., Khan, M.W., Kumar, P.S., Kempegowda, P. 2011. Clinicomicrobiological profile of urinary tract infection in south India. Indian J. Nephrol., 21(1): 30-36.

Gupta K. Addressing antibiotic resistance. Am J Med. 2002; 113 (Suppl 1A): S29S34.

Hooton TM. Clinical practice. Uncomplicated urinary tract infection. N. Engl. J. Med. 2012; 366: 1028-37.
Hussein, N.S. 2014. Clinical, Etiology and Antibiotic Susceptibility Profiles of Community- Acquired Urinary Tract Infection in a Baghdad Hospital. Med. Surgical Urol., 3(2): 1-5.

Kamat US, Fereirra A, Amonkar D, Motghare DD, Kulkarni MS. Epidemiology of hospital acquired urinary tract infections in a medical college hospital in Goa. Indian J Urol. 2009; 25: 76-80.

Orhue, P.O. 2014. Prevalence of uropathogenic bacterial isolates from urinary tract infections: A case study of university of Benin teaching hospital, Benin City, Nigeria. Int. J. Microbiol. Appl., 1(2): 18-22.

Pankaj Baral, Sanjiv Neupane, Bishnu Prasad Marasini, Kashi Ram Ghimire, Binod Lekhak, and Basudha Shrestha High prevalence of multidrug resistance in bacterial uropathogens from Kathmandu, Nepal BMC Res Notes. 2012; 5: 38.

Patel, P., and Garala, R.N. 2014. Bacteriological profile and antibiotic susceptibility pattern (antibiogram) of urinary tract infections in paediatric patients. J. Res. Med. Dent. Sci., 2(1): 20-23.

Preethishree, P., Rekha Rai, K. Vimal Kumar, K.B. Asha Pai and Pratibha Bhat U. 2016. Uropathogens and their antibiotic susceptibility pattern at a tertiary care teaching hospital in Coastal Karnataka, India. Int.J.Curr.Microbiol.App.Sci. 5(1): 23-31.

Razak, S.K., and Gurushantappa, V. 2012. Bacteriology of Urinary Tract Infection and Antibiotic Susceptibility Pattern in a Tertiary Care Hospital in South India. Int. J. Med. Sci. Public Health, 1(2): 109-112.

Shah, L.J., Vaghelam, G.M., Mahida, H. 2015. Urinary tract infection: Bacteriological profile and its antibiotic 
susceptibility in western India. Nat. J. Med. Res., 5(1): 71-74.

Sharma, A., Shrestha, S., Upadhyay, S., Rijal, P. 2011. Clinical and Bacteriological profile of urinary tract infection in children at Nepal Medical College Teaching Hospital. Nepal Med. Coll. J., 13(1): 24-26.

Singhal, A., R Sharma, M Jain, and L Vyas. Hospital and Community Isolates of Uropathogens and their Antibiotic Sensitivity Pattern from a Tertiary Care Hospital in North West India. Ann Med
Health Sci Res. 2014 Jan-Feb; 4(1): 5156.

Uwaezuoke JC, and Ogbulie JN. Antibiotic sensitivity pattern of urinary tract pathogens in port- Harcourt, Nigeria. $\mathbf{J}$ Appl Sci Environ Mgt. 2006; 10: 103-7. Wagenlehner FM, and Naber KG. Treatment of bacterial urinary tract infections: presence and future. Eur Urol. 2006; 49(2): 235-244. doi: 10.1016/ j.eururo.2005.12.017.

\section{How to cite this article:}

Pooja Gupta and Kashish Gupta. 2018. The Profile of Uropathogens and Their Antibiotic Susceptibility in IPD Adults in a Tertiary Care Hospital in North India. Int.J.Curr.Microbiol.App.Sci. 7(06): 3190-3197. doi: https://doi.org/10.20546/ijcmas.2018.706.374 